\title{
Atypical cutaneous mycobacteriosis caused by Mycobacterium avium complex
}

A 41-year-old woman presented with an ulcerated skin lesion, localized on the left thigh (Figures 1,2). The lesion had been present for 5 months; it was slowly increasing, was not painful, and measured $3 \mathrm{~cm}$ in its largest diameter. Complementary tests were carried out as serology for human immunodeficiency virus (HIV) was positive; CD4+ $\mathrm{T}$ cell count was 49 cells $/ \mathrm{mm}^{3}(<50$ cell $/ \mu \mathrm{L}) ;$ PPD and Montenegro skin test was non-reactive; and serological examination for antibodies (Paracoccidioides brasiliensis and Histoplasma capsulatum) was negative. Culture for fungi and bacteria was negative, and the histopatophological analysis of skin biopsies with Wade staining revealed numerous acid-fast bacilli resistant. Culture for mycobacteria in Loewenstein-Jensen media, after treatment with $\mathrm{N}$-acetylcysteine/ $\mathrm{NaOH}$ (Figure 3), and phenotypic identification using the PRA (PCR-restriction enzyme analysis) method revealed M. avium complex (Figure 4). The patient was started on long-term antibiotic therapy with azithromicyn $500 \mathrm{mg}$ daily and was started on HAART based on zidovudine, lamivudine, and nevirapine. After 3 months of treatment, the patient recovered with superficial scarring. Treatment was well tolerated. At the follow-up examinations after $4,8,12$, and 22 weeks, a pronounced regression of the lesions was observed (Figure 5). Nontuberculous mycobacteria are important opportunistic human pathogens with systemic impairment of immunity, and the Mycobacterium avium complex (MAC) has emerged as a major human pathogen. ${ }^{1}$ Cutaneous MAC disease occurs by direct inoculation (trauma, surgery, injection) and is characterized by skin lesions, such as ulceration, abscess, or erythematous plaque. The lesions are indolent, with little or no lymph node reaction. ${ }^{2}$ A study held in a reference laboratory in Brazil revealed that the skin was affected only in $1.3 \%$ of cases with isolation of M. kansasii, M. abscessus, and M. scrofulaceum. ${ }^{3}$ Azithromycin is a great promise for treatment of infections caused by these acidfast bacteria. ${ }^{4}$
Authors

Cassio Porto Ferreira,

Master's degree ${ }^{1}$

Ziadir Francisco

Coutinho, Master's

degree $^{2}$

Maria Cristina Lourenço, $\mathrm{PhD}^{3}$

Adalgiza da Silva Rocha, $\mathrm{PhD}^{4}$

Carlos José Martins,

Professor $^{5}$

${ }^{1}$ Infectious Dermatology Laboratory, IPEC/ FIOCRUZ, Rio de Janeiro, Brazil.

${ }^{2}$ ENSP/FIOCRUZ ${ }^{3}$ Bacteriology Laboratory, IPEC/FIOCRUZ, Rio de

Janeiro, Brazil.

${ }^{4}$ Mycobacteriology

Laboratory, IOC/

FIOCRUZ, Rio de Janeiro, Brazil.

${ }^{5}$ Department of

Dermatology, UNIRIO, Rio de Janeiro, Brazil.

Figure 1: Ulcerated lesion on the left thigh.

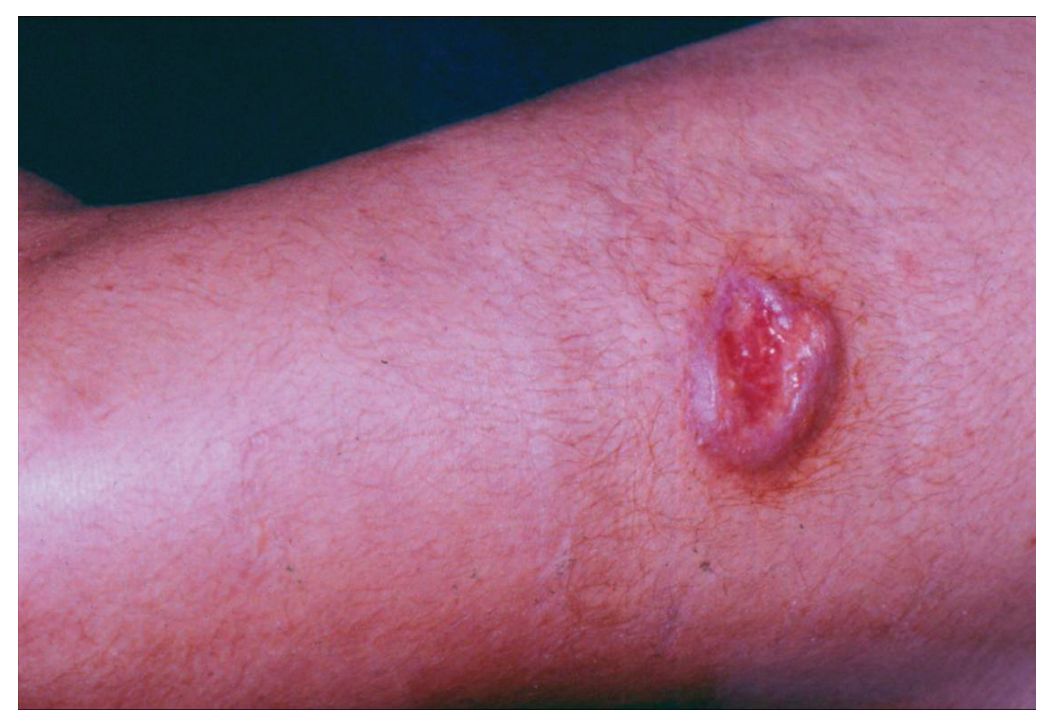

Submitted on: 09/24/2009 Approved on: 10/27/2009

Correspondence to: Cassio Porto Ferreira Travessa Regina 79/85, Centro

Nova Iguaçu - RJ - Brazil ZIP code: $26210-350$ Phone: +55-21-27679722 Fax: +55-21-27688008 E-mail: drcassioferreira@ yahoo.com.br

We declare no conflict of interest. 
Figure 2: More detail, showing its granular center.

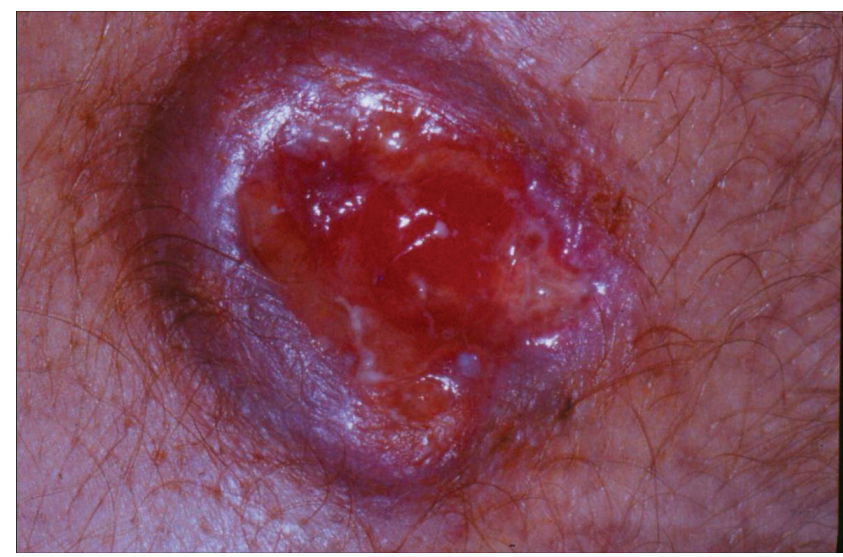

Figure 3: Loewenstein-Jensen mean, after treatment with $\mathrm{N}$ acetylcysteine/NaOH: Mycobacterium avium complex (Runyon's group III: non-chromogenic).

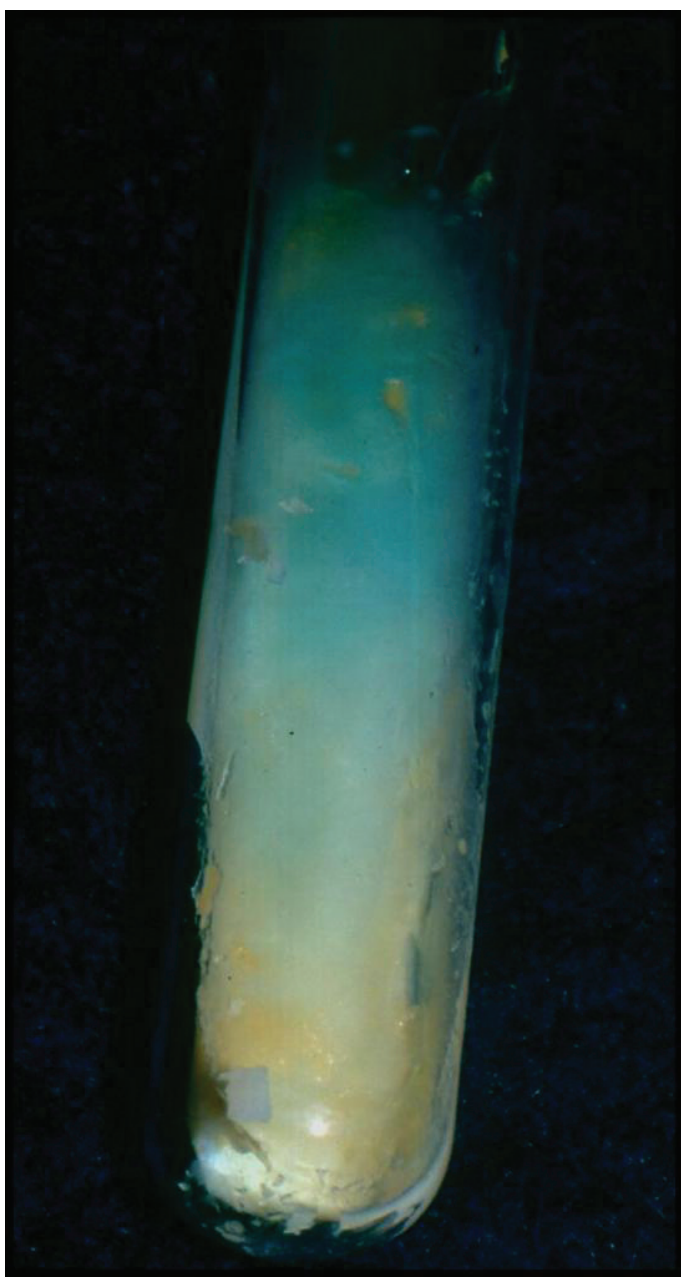

Figure 4: Phenotypic identification, using the PRA method: Mycobacterium avium complex.

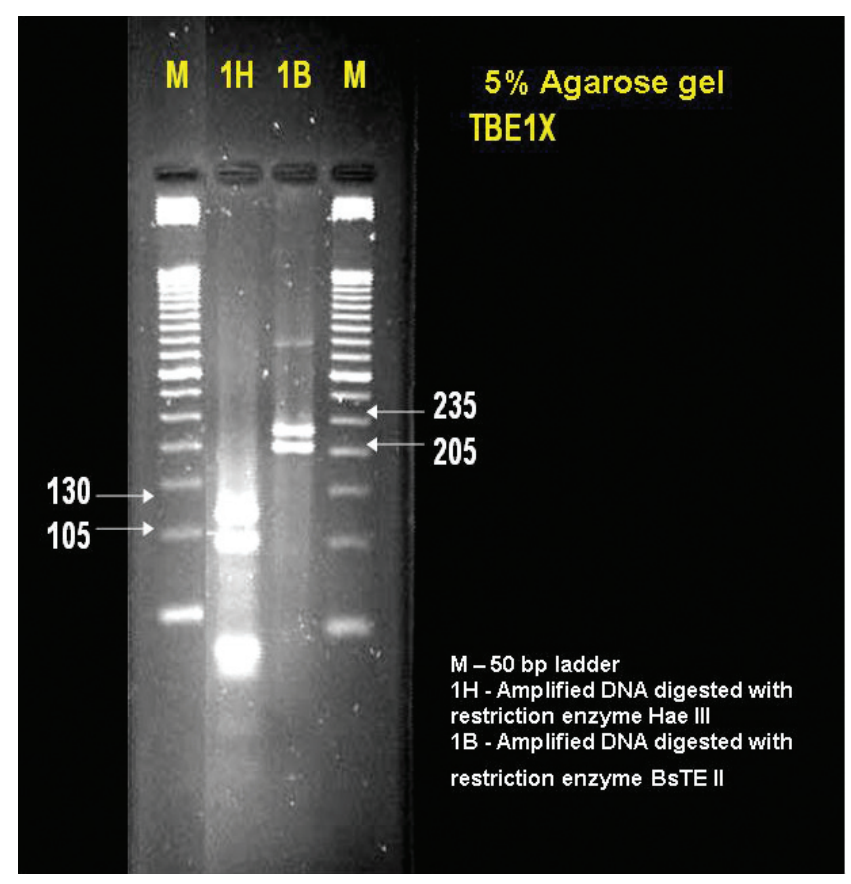

Figure 5: Healed lesion.

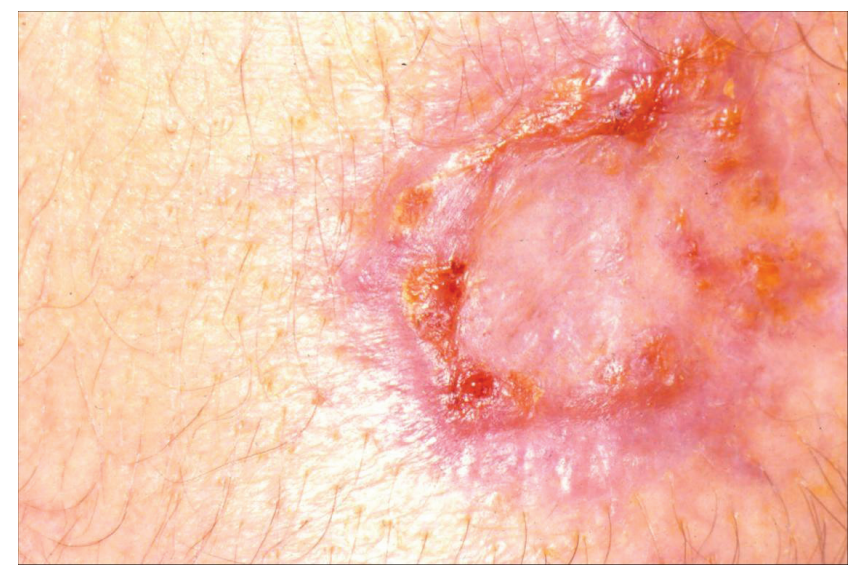

\section{REFERENCES}

1. Field SK, Cowie RL. Lung disease due to the more common nontuberculous mycobacteria. Chest 2006; 129(6):1653-72.

2. Piersimoni C, Scarparo C. Extrapulmonary infections associated with nontuberculous mycobacteria in immunocompetent persons. Emerg Infect Dis 2009; 15(9):1351-57.

3. Barreto AMW, Campos CED. Micobactérias "não tuberculosas" no Brasil. Bol Pneumol Sanit 2000; 8(1):3-32.

4. Rapp RP, McCraney SA, Goodman NL, Shaddick DJ. New macrolide antibiotics: usefulness in infections caused by mycobacteria other than Mycobacterium tuberculosis. Ann Pharmacother. 1994; 28(11):1255-63. 